\title{
Prof. Dr. S. Daum 80 Jahre
}

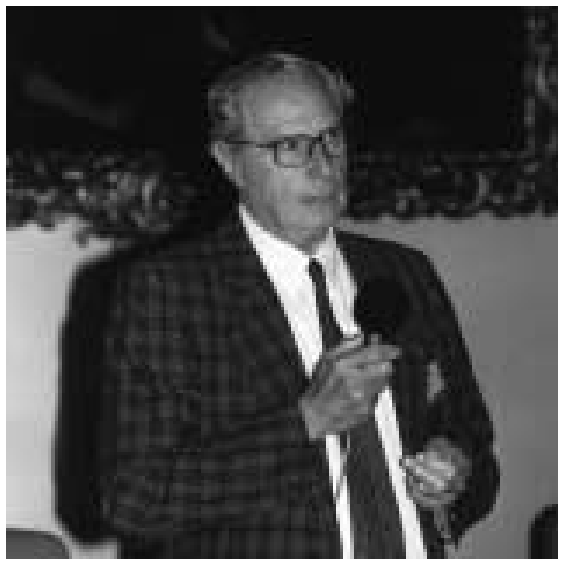

Prof. Dr. Severin Daum

Prof. Dr. Severin Daum feiert am 26. März 2003 seinen 80. Geburtstag.

Aufgewachsen in der Nähe von Prag, wo sein Vater Präsident des dortigen Patentamtes war, spiegelt sein Lebensweg die Wirren des 20. Jahrhunderts wider. Nach dem Abitur 1942 war ihm der Weg zum Studium versperrt, da die deutschen Machthaber des „Protektorats“ im Kampf gegen die tschechische Intelligenz alle Hochschulen geschlossen hatten. So begann er das Studium in Jena, musste sich aber nach 3 Semestern 1943 als Laborant in einem Krankenhaus in Prag verdingen. Als der Zweiten Weltkrieg dann zu Ende war, musste er 1946 das Medizinstudium in Prag neu beginnen. Doch schon nach 2 Jahren kam erneut das Aus, denn nachdem die Kommunisten die Regierung in Prag wieder beherrschten, war Daum wegen seiner kritischen Einstellung zum System als Student unerwünscht. So blieb ihm nichts übrig, als wieder als Laborant zu arbeiten. Erst mit dem Tode Stalins 1953 war die Fortsetzung des Studiums mit Abschluss und Pro- motion 1956 möglich. Bereits in dieser Zeit wirkte er an der Einrichtung der ersten extrakorporalen Dialyse in seinem Land, der fünften in Europa überhaupt, mit. 1957 wechselte er, von Prof. Dr. F. Herles berufen, in die Kardiologie und beteiligte sich am Aufbau eines Herzkatheterplatzes in der II. Med. Klinik der KarlsUniversität. Reisen ins Ausland blieben ihm aber ebenso verwehrt wie eine Habilitation. Durch die politischen Umstände erzwungen musste Daum 1962 die Klinik verlassen und kam in das Institut für Experimentelle Therapie in Prag, wo er zum zweiten Mal einen Herzkatheterplatz einrichten konnte. Hier beschäftigte er sich auch intensiv mit der Bestimmung der Diffusionskapazität der Lunge für Kohlenmonoxid. Am Ende des „Prager Frühlings“" (21. August 1968) konnte Daum mit viel Glück aus der ČSSR ausreisen und kam in die Abteilung von Prof. Dr. H. Herzog am Kantonsspital in Basel, wo er eine Oberarztstelle inne hatte. Erst Ende 1968 konnte ihm seine Frau, ebenfalls Ärztin, mit damals zwei Kindern nachfolgen. In Basel widmete sich Daum erneut der Rechtsherzkatheterisation, zunächst mit dem Katheter nach Grandjean, bald danach nach Swan-Ganz (beschrieben 1967 bzw. 1970; Ganz war Landsmann von Daum) und auch nach Dotter-Lukas (zur einseitigen Okklusion eines Pulmonalarterienhauptastes zur präoperativen Simulation einer Pneumonektomie). 1971 wechselte Daum in das Klinikum rechts der Isar der Technischen Universität München, wo er in der kardiologischen Klinik unter Prof. Dr. H. Blömer eine pneumologische Arbeitsgruppe mit großem Lungenfunktionslabor aufbauen konnte. Dort habilitierte er sich 1972, 1978 wurde er zum apl. Professor ernannt. 1990 schied er altershalber aus der Klinik aus.

Auch im „Ruhestand“ blieb Daum weiterhin aktiv. Schon unmittelbar nach dem Fall des kommunistischen Systems in seiner Heimat 1989 hatte er Kontakt mit der Karls-Universität Prag geknüpft und eine Kooperation zwischen dieser und der LudwigMaximilians-Universität München vermittelt. Im Rahmen derer 
hielt er Vorlesungen in Prag und wurde Mitglied des dortigen Wissenschaftsrats. 1991 wurde er vom (damals noch tschechoslowakischen) Präsidenten V. Havel selbst zum ordentlichen Professor der Karls-Universität ernannt. Das Angebot, die Leitung einer medizinischen Klinik zu übernehmen, schlug er aber aus. Bis heute engagiert sich Daum in dieser Kooperation.

Stets hatte Daum in politisch schwieriger Zeit versucht, aus der ČSSR heraus Kontakt mit seinen Kollegen im Westen zu halten. Da Reisen zu Kongressen westlicher Gesellschaften nicht erlaubt wurden, forcierte er zusammen mit anderen Kollegen aus mehreren Ländern im Osten wie im Westen die Gründung einer europäischen Gesellschaft, nämlich der Societas Europea Physiologiae Clinicae Respiratoriae (SEPCR), an deren Spitze dem kommunistischen System nur ein Franzose, so Prof. Dr. P. Sadoul, genehm war (und die 1990 mit der Societas Europaea Pneumologica (SEP) zur European Respiratory Society (ERS) verschmolz). Umgekehrt war er später im Westen bemüht, mit seinen früheren Kollegen in Osteuropa und insbesondere in der damaligen ČSSR Kontakt zu halten. Er verschaffte ihnen Einladungen zu Kongressen im Westen und besorgte ihnen Reisestipendien. So verwundert es nicht, dass er nach dem Ende der kommunistischen Herrschaft in seinem Heimatland und noch in drei anderen ehemaligen Ostblockländern die Ehrenmitgliedschaft in de- ren pneumologischen Gesellschaften erhielt. Herausragend ist die Ehrenmitgliedschaft in der tschechoslowakischen Gesellschaft für Nephrologie (1990) und der deutschen Gesellschaft für Pneumologie (1998). Darüber hinaus erhielt er zahlreiche Auszeichnungen im In- und Ausland, die anzuführen eine lange Liste füllen würde. Beispielhaft seien genannt 1966 die Verleihung der Robert-Koch-Medaille, 1998 der Purkynje-Medaille und 2000 die Ehrendoktorwürde der Universität Trnava (40 km nordöstlich von Preßburg, SK), der ältesten Jesuiten-Universität (gegr. 1635) der k. u. k. Monarchie. Mehrmals reiste Daum zu Gastvorlesungen nach Osteuropa und in den fernen Osten.

Alle seine Schüler, von denen sich drei habilitieren konnten (dazu nach 1990 noch 4 Habilitanten in Prag) und die nun selbst Chefärzte sind, haben ihm viel zu danken. Alle, die ihn von Kongressen her kennen, werden seine Kommentare zu vorgetragenen Ergebnissen mit Hinweis auf frühere Publikationen und seine markante Ausdrucksart in Erinnerung haben.

Heute lebt Prof. Dr. Daum zusammen mit seiner Frau weiterhin in München. Seine 4 Kinder, davon 2 selbst wieder Ärzte, haben ihm schon 2 Enkel beschert, welche ihn immer noch frisch und munter halten. Dass dies noch lange so bleiben möge, wünschen wir ihm von Herzen. 